\title{
Genotypic Identification of Cystoisospora in Immunocompromised Patients Using $\mathrm{T}_{\mathrm{m}}$-Variation Analysis
}

\author{
Maha M.A. Basyoni',*, Hany Ahmed Fouad Elghobary² \\ ${ }^{1}$ Parasitology Department, Faculty of Medicine, Cairo University, Egypt; ${ }^{2}$ Clinical and Chemical Pathology Department, Faculty of Medicine, \\ Cairo University, Egypt
}

\begin{abstract}
Cystoisospora is responsible for morbidity in immunocompromised patients. PCR is sensitive for diagnosing Cystoisospora; however, it needs reevaluation for differential molecular diagnosis of cystoisosporiasis. We aimed at evaluating melting curve analysis (MCA) after real-time PCR (qPCR) in diagnosis and genotyping of Cystoisospora as an alternative to conventional PCR. We included 293 diarrheic stool samples of patients attending the Department of Clinical Oncology and Nuclear Medicine of Cairo University Hospitals, Egypt. Samples were subjected to microscopy, nested PCR (nPCR), and qPCR targeting the internal transcribed spacer 2 region (ITS2) of the ribosomal RNA ( $r$ RNA) gene followed by melting temperatures $\left(\mathrm{T}_{\mathrm{m}} \mathrm{s}\right)$ analysis and comparing the results to PCR-RFLP banding patterns. Using microscopy and ITS2-nPCR, 3.1\% and 5.8\% of cases were Cystoisospora positive, respectively, while $10.9 \%$ were positive using qPCR. Genotyping of Cystoisospora by qPCR-MCA revealed 2 genotypes. These genotypes matched with 2 distinct melting peaks with specified $\mathrm{T}_{\mathrm{ms}}$ at $85.8^{\circ} \mathrm{C}$ and $88.6^{\circ} \mathrm{C}$, which indicated genetic variation among Cystoisospora isolates in Egypt. Genotype II proved to be more prevalent (65.6\%). HIV-related Kaposi sarcoma and leukemic patients harbored both genotypes with a tendency to genotype II. Genotype I was more prevalent in lymphomas and mammary gland tumors while colorectal and hepatocellular tumors harbored genotype II suggesting that this genotype might be responsible for the development of cystoisosporiasis in immunocompromised patients. Direct reliable identification and differentiation of Cystoisospora species could be established using qPCR-T $\mathrm{ms}$ analysis which is useful for rapid detection and screening of Cystoisospora genotypes principally in high risk groups.
\end{abstract}

Key words: Cystoisospora, melting curve analysis, qPCR

\section{INTRODUCTION}

Cystoisospora, formerly called Isospora, after taxonomic re-arrangements, were proved to infect human beings solely [1]. The display of cystoisosporiasis is inconsistent, depending on the parasite aggression as well as the host immune condition [2]. Diarrheal cystoisosporiasis may affect both immunocompetent and immunosuppressed individuals. However, it seems to occur more frequently in the latter. Thus, it was described as an opportunistic protozoan [3]. Despite that patients with cystoisosporiasis usually improve within a few days after commencement of treatments, relapses of diarrhea have been reported in a large number of cases with failing to spot Cystoisos-

- Received 12 June 2017, revised 4 November 2017, accepted 24 November 2017. *Corresponding author (mmabulmagd@kasralainy.edu.eg; drmahaabu@gmail.com) (c) 2017, Korean Society for Parasitology and Tropical Medicine This is an Open Access article distributed under the terms of the Creative Commons Attribution Non-Commercial License (http://creativecommons.org/licenses/by-nc/4.0) which permits unrestricted non-commercial use, distribution, and reproduction in any medium, provided the original work is properly cited. pora as the cause of recurrent diarrhea. This reinfection may be missed as oocysts have thin translucent walls and are usually scanty and intermittent in stool samples which in turn make microscopic examination results unremarkable [4].

Staining for detection of Cystoisospora, as auramine-O, reported $100 \%$ sensitivity and specificity compared to modified Zeihl-Neelsen stain, while iodine staining wet mount showed 54\% sensitivity. However, repeated multiple testing using expertise microscopist is required [5]. As a result of the difficulty associated with identifying Cystoisospora in fecal samples, diseases allied with its genotypes are likely underdiagnosed, and their outburst reports may be underestimated. Subsequently, more sensitive tools for detection of Cystoisospora are inevitable especially for species identification. Cystoisospora-specific molecular analysis is accessible for much more sensitive screening [6].

Muller et al. [7] described nested PCR (nPCR) with southern blot hybridization for the detection of light C. belli infections. However, these are very lengthy and not competent for 
epidemiologic purposes. Moreover, PCR primers recognizing conserved DNA sequences of Cystoisospora were used in intestinal tissue biopsy and were confirmed at replicate tissue analysis [3]. Taniuchi et al. [8] eluded diagnosis using conventional methods by suggesting higher sensitivity of molecular approaches compared to microscopy. They reported that multiplex PCR detected C. belli in stools with $93 \%$ sensitivity compared to microscopy, and some of $C$. belli null samples tested positive by real-time PCR assay. Different molecular targets of protozoa could be used by real-time PCR assay for potent diagnosis in epidemiologic studies [9]. Real-time PCR with MCA of coccidian oocysts in different diagnostic samples could be sensitively used and it consistently discriminated different isolates [10]. Thus, herein we proposed a molecular diagnosis using qPCR-MCA for genotyping of cystoisosporiasis in immunocompromised patients with diarrhea to investigate this approach as a potential assay for genotyping Cystoisospora that may elude diagnosis using tedious conventional approaches.

\section{MATERIALS AND METHODS}

\section{Patients}

This study included a total of 293 diarrheic stool samples (198 males and 95 females). Patients' ages ranged from 15 to 55 years with a mean age of 25.3 years; attending the Department of Clinical Oncology and Nuclear Medicine of Cairo University Kasr Al Ainy Hospitals from September 2015 to December 2016. Patients attended for diagnosis and treatment of various types of tumors, including HIV-related Kaposi's sarcoma (3 patients), hematological malignancies, leukemias and lymphomas (134 patients), colorectal carcinomas (48 patients), hepatocellular tumors (76 patients), and mammary gland tumors (32 patients). All stool samples were examined in the research laboratory of Parasitology Department, Faculty of Medicine, Cairo University.

\section{Direct microscopy of fecal smears}

All samples were investigated by microscopic examinations of wet mounts. Stools were then concentrated by a formalinethyl acetate technique, stained using modified acid fast stain and microscopically examined using low-power $(\times 10)$ and high-power $(\times 40)$ objectives.

\section{Specimens and DNA extraction}

All stool samples were stored at $-20^{\circ} \mathrm{C}$ for less than 6 months before DNA extraction. DNA was extracted using QIAamp DNA Stool Mini Kit (Qiagen, Hilden, Germany) according to the manufacturer's protocol. Potential inhibitors were removed by further purification with the QIA quick PCR purification kit (QIAGEN Inc.) according to the manufacturer's instructions. Purified DNA was stored at $-20^{\circ} \mathrm{C}$ until used.

\section{nPCR of ITS2 rRNA gene}

According to Taniuchi et al. [11] and Jongwutiwes et al. [2], a nPCR of the ITS2 rRNA gene included 2 consecutive PCR reactions. The first reaction employs an external pair of primer sets (Fermentas UAB, Vilnius, Lithuania) Iso-18SF0 (5'- TGGTTGATCCTGCCAGTA-3') and Iso-28SR0, (5'-AAGGCTCAATCAAGAACCTCCG-3') which amplify the DNA fragment spanning the SSU rRNA, ITS-1, 5.8S rRNA and ITS-2 regions of Cystoisospora. The second reaction contained 2 nested primers internal to the first primer pair and amplified a 404 bp fragment. These were Ib-213 F (5'-GGATATTCCCTGCAGCATGT-3') and a reverse one: Ib-213R (5'-CGGGACACAACTCAACACTG-3') (GenBank accession no. AF443614). Amplification was done using $12.5 \mu$ PCR Master Mix (product no. B2281; Thermo Scientific, Runcorn, UK), $1 \mu \mathrm{l}(200 \mathrm{nmol} / \mathrm{L})$ of each forward and reverse primer, $2.5 \mu \mathrm{l}$ of template DNA, $0.1 \mu \mathrm{l} \mathrm{Taq}$ polymerase ( $5 \mathrm{U} / \mu \mathrm{l}$ ) (product no. EP3501, Thermo Scientific) and $8 \mu \mathrm{l}$ of sterile distilled water to complete a total volume of $25 \mu \mathrm{l}$ using thermal cycler (Biometra, Göttingen, Germany). The thermal cycling conditions were the same in both PCR reactions; denaturation at $94^{\circ} \mathrm{C}$ for $40 \mathrm{sec}$, annealing at $64^{\circ} \mathrm{C}$ for $40 \mathrm{sec}$, extension at $74^{\circ} \mathrm{C}$ for 5 min for 35 cycles of amplification. The amplified products were separated by electrophoresis on $2 \%$ agarose gel and visualized under a transilluminator after staining with ethidium bromide.

\section{qPCR-MCA}

It was carried according to Hove et al. [9] targeting ITS2 region of rRNA gene. The amplification was performed using the forward primer Ib-40F (5'-ATA TTC CCT GCA GCA TGT CTG TTT-3') and reverse primer Ib-129R (5'-CCA CAC GCG TAT TCC AGA GA-3'), that amplified a 89 bp fragment of ITS2 region of rRNA gene. Double-labeled probe Ib-81Taq (FAM-5'CAA GTT CTG CTC ACG CGC TTC TGG-3'-BHC1) (Invitrogen, Carlsbad, California, USA) were used. All qPCR assays were performed with the iCycler iQ real-time PCR detection system (Bio-Rad Laboratories, Hercules, California, USA). The final reaction mix contained 13 iQ SYBR Green Supermix (In- 
vitrogen) $400 \mathrm{nM}$ for R-Cystoisospora, F-Cystoisospora, and sterile $\mathrm{dH}_{2} \mathrm{O}$ adjusted to a final volume of $25 \mathrm{ml}$. Standard curves for all qPCR assays were prepared by 10 -fold dilution of $C$. belli DNA. We used the standard curves to identify the reference and alternate samples. As the MCA method relies on saturating DNA dyes, the standard and variant samples produce single $\mathrm{T}_{\mathrm{m}}$ peaks that diverge by $0.7-1.2^{\circ} \mathrm{C}$ [12]. This allowed us to identify genotypes by their single $\mathrm{T}_{\mathrm{m}}$ peak and their association with the standard $\mathrm{T}_{\mathrm{m}}$ curve with subsequent identification of genotypes by their shifted $\mathrm{T}_{\mathrm{m}}$ curves compared to the standard curves. The PCR cycling conditions were $3 \mathrm{~min}$ at $95^{\circ} \mathrm{C}$, followed by 40 cycles of denaturing at $95^{\circ} \mathrm{C}$ for $40 \mathrm{sec}$, annealing at $62^{\circ} \mathrm{C}$ for $40 \mathrm{sec}$, and extension at $72^{\circ} \mathrm{C}$ for $40 \mathrm{sec}$. After finishing of 40 cycles PCR amplification, the PCR products were melted by elevating the temperature from $40^{\circ} \mathrm{C}$ to $95^{\circ} \mathrm{C}$ at a rate of $1^{\circ} \mathrm{C} / \mathrm{min}$. Melting curves were generated by plotting for each sample the rate of change in fluorescence against the increase in temperature. The iCycler iQ software displayed the records collected during $\mathrm{MCA}$ as $-\mathrm{dF} / \mathrm{dT}$ vs temperature. A sample was considered positive when the icycler determined a crossing point in the quantification analysis screen. $\mathrm{T}_{\mathrm{m}} \mathrm{s}$ were detected by melting peaks of the curve.

\section{Correlation of RFLP banding patterns to the corresponding $\mathrm{T}_{\mathrm{m}} \mathrm{P}$ peaks}

After the qPCR amplification of ITS2-rRNA gene and MCA, the PCR products belonging to the detected $\mathrm{T}_{\mathrm{m}} \mathrm{s}$ were digested using RFLP with the enzyme AluI (Thermo Scientific, Waltham, Massachusetts, USA). The restriction digestion reaction consisted of a $10 \mathrm{Ul}$ aliquot of PCR product, $1 \mathrm{U}$ of AluI, $2 \mathrm{Ul}$ of acetylated BSA (Thermo Scientific), and made up to a total volume of 30 Ul with nuclease-free water, then incubated in a $37^{\circ} \mathrm{C}$ water bath for $1 \mathrm{hr}$. Restriction fragments were separated on $2 \%$ agarose gels and visualized under UV illumination to observe different banding patterns and to compare these patterns with the corresponding $\mathrm{T}_{\mathrm{m}} \mathrm{s}$.

\section{Specificity of qPCR assay}

To determine the analytical specificity of the qPCR, DNAs were evaluated separately. We used in each run: $(a)$ a distilled water sample as a negative control. (b) Cystoisospora control DNA extracted from an unpreserved human fecal sample in which the presence of Cystoisospora oocysts was confirmed by microscopy. (c) DNAs isolated from Schistosoma mansoni, Fasciola gigantica, Cyclospora cayetanensis, Entamoeba histolytica, Entamoeba dispar, Giardia lamblia, Cryptosporidium parrum, Enterocytozoon bieneusi, Encephalitozoon intestinalis. E. histolytica, E. dispar, and G. lamblia ( $\mathrm{n}=10$ for each).

\section{Statistical analysis}

Means $( \pm \mathrm{SD})$ of the $\mathrm{T}_{\mathrm{m}} \mathrm{s}$ in duplicate independent assays were calculated.

\section{Ethical considerations}

This study was conducted in compliance with the Helsinki Declaration. The research was approved by the Scientific Research Ethical Committee, Faculty of Medicine, Cairo University (archiving no. 15/2017). All procedures were explained to patients and a written or thumb printed consent was obtained.

\section{RESULTS}

Among the 293 diarrheic stool samples included in the present study, Cystoisospora isolates were detected in 9 cases (3.1\%) and 17 cases (5.8\%) by microscopy and nPCR, respectively. While by using qPCR, Cystoisospora was detected in 32 samples (10.9\%) (Table 1). Using the ITS2-rRNA gene amplification by qPCR followed by MCA, we demonstrated variation in $T_{\mathrm{m}} \mathrm{s}$ between the standard curves and the tested samples. Two different $\mathrm{T}_{\mathrm{m}} \mathrm{s}$ were found, including $85.8^{\circ} \mathrm{C}, 88.6^{\circ} \mathrm{C}$. Each $\mathrm{T}_{\mathrm{m}}$ corresponds to a specific distinct curve peak which in turn implies for a specific genotype, facilitating its identification (Fig. 1A-D). Consistent $\mathrm{T}_{\mathrm{m}} \mathrm{s}$ were obtained for each genotype in duplicate independent assays with inter-assay variation less than $0.3^{\circ} \mathrm{C}$ (Table 2). As a result, 2 genotypes with 2 different

Table 1. Diagnostic yield of microscopy, nPCR, and qPCR-ITS2 in the studied group

\begin{tabular}{|c|c|c|c|c|c|}
\hline \multirow{2}{*}{ qPCR } & \multicolumn{2}{|c|}{$\mathrm{nPCR}$} & \multicolumn{2}{|c|}{ Microscopy } & \multirow{2}{*}{ Total } \\
\hline & Positive & Negative & Positive & Negative & \\
\hline Positive & 17 & 15 & 9 & 23 & 32 \\
\hline Negative & 0 & 261 & 0 & 261 & 261 \\
\hline Total & 17 & 276 & 9 & 284 & 293 \\
\hline
\end{tabular}


A

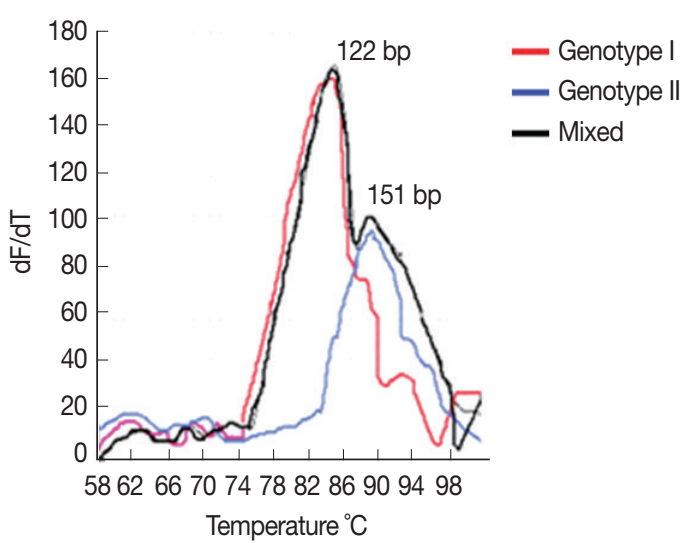

C

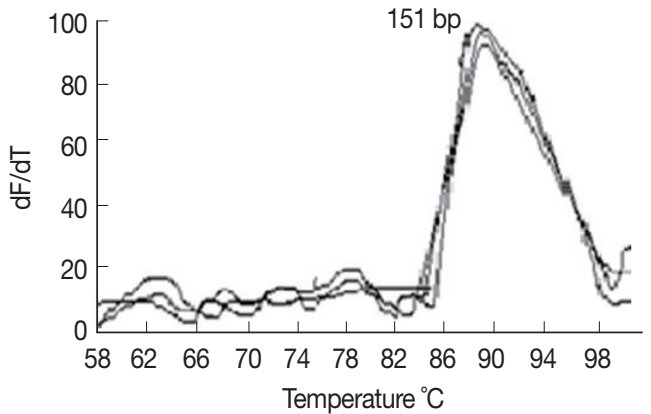

B

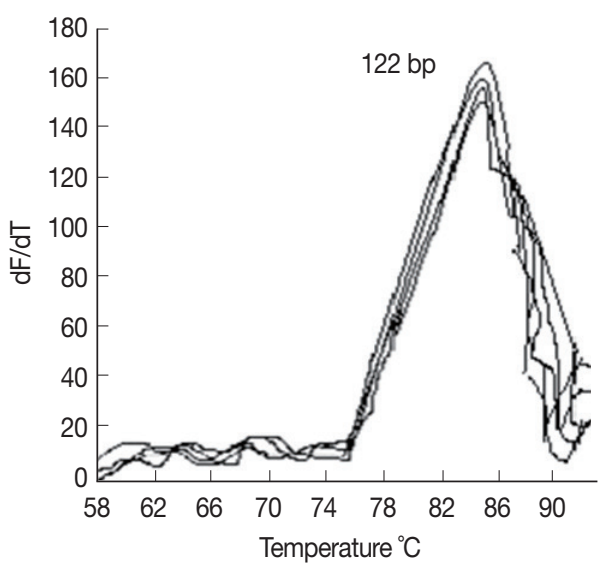

D

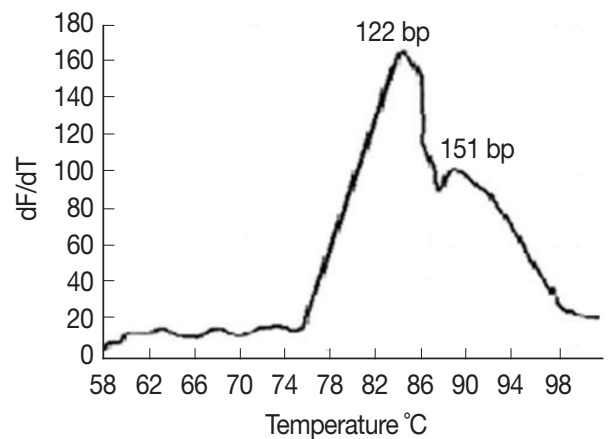

Fig. 1. (A) Melting curve analysis of $\mathrm{qPCR}$ amplification products of Cystoisospora. The amplified DNA products represented as distinct melting peaks with specified $T_{m s}\left(88.6^{\circ} \mathrm{C}\right.$ and $\left.85.8^{\circ} \mathrm{C}\right)$. Each $T_{m}$ corresponds to a specific genotype. (B) Melting curve of confirmed samples of Cystoisospora harboring genotype I showing distinct melting peaks at $85.8^{\circ} \mathrm{C}$. (C) Melting curve of confirmed samples of Cystoisospora harboring genotype II showing distinct melting peaks at $88.6^{\circ} \mathrm{C}$. (D) Melting curve of a confirmed sample of Cystoisospora harboring both genotypes || and I showing 2 distinct melting peaks at $88.6^{\circ} \mathrm{C}$ and $85.8^{\circ} \mathrm{C}$, respectively.

Table 2. Mean $T_{m S}$ of qPCR and RFLP product size of amplified Cystoisospora DNAs

\begin{tabular}{lcccc}
\hline Genotype & No. (\%) & $T_{m}{ }^{(C)}$ & Product size (bp) & Confidence interval (99\%) $^{\star}$ \\
\hline Genotype I & $10(31.3)$ & 85.8 & 55,67 & $85.7-85.9$ \\
Genotype II & $21(65.6)$ & 88.6 & 130,21 & $88.5-88.6$ \\
\hline
\end{tabular}

${ }^{*}$ Confidence interval $=T_{m} \pm t \times s / \sqrt{ }$, where $t=t$ statistic for $n-1 d f, S=$ standard deviation, and $n=$ number of replicates.

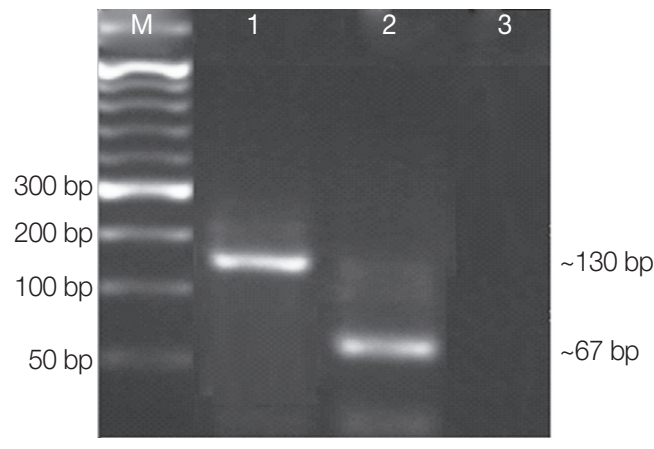

Fig. 2. Agarose gel electrophoresis of RFLP profiles of ITS2 qPCR amplified Cystoisospora products using ALU I restriction enzyme. Lane M, 50 bp molecular weight marker; lane 1, confirmed sample (genotype II: 130 bp); lane 2, confirmed sample (genotype I: 67bp); lane 3, control. peaks; genotype-I and genotype-II were found corresponding to $2 \mathrm{~T}_{\mathrm{m}} \mathrm{s} ; 85.8^{\circ} \mathrm{C}$ and $88.6^{\circ} \mathrm{C}$, respectively. Among 32 individuals harboring Cystoisospora isolates, 21 were harboring genotype-II isolates (65.6\%) while genotype-I was detected in 10/32 (31.3\%), and there was 1 sample which harbored both genotypes. Genotype I was detected in 5 leukemic patients, 3 lymphoma patients, and 2 patients with mammary gland tumors. Genotype II was detected in 11 leukemic patients, 6 colorectal, 2 hepatocellular carcinoma (HCC), and 2 HIV-related Kaposi carcinoma. Both genotypes were detected in 1 HIV-related Kaposi carcinoma. By using restriction enzyme AluI for digestion of amplified qPCR products targeting the ITS2 gene, we found that DNA samples that melted at $85.8^{\circ} \mathrm{C}$ 
$\mathrm{T}_{\mathrm{m}}$ resulted in DNA bands of 55 and $67 \mathrm{bp}$ which corresponds to genotype I. Likewise, DNAs that melt at $88.6^{\circ} \mathrm{C} \mathrm{T}_{\mathrm{m}}$ resulted in different bands of 21 and $130 \mathrm{bp}$ which correspond to genotype II (Fig. 2; Table 2). Diagnostic yields of qPCR-ITS2 showed the highest sensitivity of 100\%, nPCR showed a sensitivity of $53.1 \%$, while microscopy had the least sensitivity of $28.1 \%$. All assays were $100 \%$ specific.

\section{DISCUSSION}

Little is known about characterization of Cystoisospora genotypes from humans and animals [6]. In Egypt, cystoisosporiasis is diagnosed sporadically, with more prevalence among the immunocompromised patients, especially those with HIV and cancers. However, it may be under-valuated and most likely higher detection could be during routine investigations of target groups. In 2006, Isospora hominis have been documented in Egypt with a prevalence reaching $7.7 \%$ [13]. To address this concern, we employed the ITS2-rRNA gene amplification by qPCR followed by MCA. During our search through literatures, few studies analyzed species/strain variation in Cystoisospora targeting the ITS2 rRNA gene $[2,9,11]$.

ITS regions are non-coding areas among 28S, 5.8S, and $18 \mathrm{~S}$ rRNA genes and are extremely preserved through diverse species. ITS2 sequence is considered a barcode as it is highly preserved, easy to be amplified, and allows high discrimination of closely related groups $[14,15]$. Consequently, the qPCR assay described in the current study allowed Cystoisospora diagnosis with improved sensitivity when compared to nPCR assay. Moreover, this qPCR has the prospective to reveal few oocysts shedding Cystoisospora patients as it depends on incorporating a specific intercalating dye; SYBR Green which is a doublestranded DNA binding dye that results in fluorescence emission curves when binding to the PCR product after each extension step. Thus, avoids electrophoresis of amplicons and allows quantitation through detection of the cycle $(\mathrm{Ct})$ at which the amplification initiates [16]. Moreover, Ririe et al [17] reported the advantage of MCA over the conventional PCR that qPCR products can be differentiated during amplification by analysis of melting curves whose shape is a property of GC content, length and sequence. MCA allows differentiation of diverse genotypes relying on variations in their shapes and $\mathrm{T}_{\mathrm{m}} \mathrm{S}$ shift as a result of variable bond strengths connecting base pairs [18]. Consequently, we interpret the results of the qPCR$\mathrm{MC}$ depending on the $\mathrm{T}_{\mathrm{m}} \mathrm{S}$ of the specific amplicons which were sufficiently different and constant to allow differentiation of the products. In our study MCA yielded 2 melting peaks $\left(\mathrm{T}_{\mathrm{m}} \mathrm{s}\right)$, each corresponds to a specific genotype of Cystoisospora. $\mathrm{T}_{\mathrm{m}} \mathrm{s}$ were consistent, with inter-assay variations less than 0.3 and were wide apart allowing easy discrimination between the different MCs. Genotype II belonging to $88.6^{\circ} \mathrm{C} \mathrm{T}_{\mathrm{m}}$ was more prevalent than the other genotype suggesting that this genotype is more responsible for cystoisosporiasis in Egypt. Notably, we found that qPCR-MCA achieved 100\% sensitivity compared to microscopy (28.1\%) and nPCR (53.1\%). Both latter assays had 23 and 15 false negative cases, respectively, which were properly detected by qPCR. What is more, on comparing RFLP products to the corresponding $T_{\mathrm{m}} \mathrm{s}$, we found 2 different banding patterns that match to the 2 variant $\mathrm{T}_{\mathrm{m}} \mathrm{s}$. Subsequently, these results confirm the genetic variation among Cystoisospora isolates, achieving analogous results to the qPCR-MCA and proving $100 \%$ sensitivity and specificity for qPCR-MCA.

In conclusion, our results highlighted Cystoisospora infection in Egypt with 2 distinct genotypes and specifically approaching immunocompromised patients. Moreover, ITS-2 rRNAMCA offered rapid, sensitive, specific approach than nPCR as it overcomes post amplification manipulations, the need for restriction digestion study and further, qPCR offers easier interpretation of MCA results than visual assessment of stained gels. Accordingly, the potential of establishing $\mathrm{qPCR}-\mathrm{T}_{\mathrm{m}} \mathrm{s}$ analysis for rapid detection and screening of Cystoisospora genotypes in case of endemic population as routine screening of high risk groups should be considered.

\section{CONFLICT OF INTEREST}

All authors declare that they have no conflicts of interest.

\section{REFERENCES}

1. Lindsay DS, Dubey JP, Blagburn BL. Biology of Isospora spp. from humans, nonhuman primates, and domestic animals. Clin Microbiol Rev 1997; 10: 19-34.

2. Jongwutiwes S, Putaporntip C, Charoenkorn M, Iwasaki T, Endo T. Morphologic and molecular characterization of Isospora belli oocysts from patients in Thailand. Am J Trop Med Hyg 2007; 77: $107-112$.

3. Murphy SC, Hoogestraat DR, Sen Gupta DJ, Prentice J, Chakrapani A, Cookson BT. Molecular diagnosis of cystoisosporiasis using extended-range PCR screening. J Mol Diagn 2011; 13: 359362.

4. Bialek R, Binder N, Dietz K, Knobloch J, Zelck UE. Comparison 
of autofluorescence and iodine staining for detection of Isospora belli in feces. Am J Trop Med Hyg 2002; 67: 304-305.

5. Ahmed NH, Chowdhary A. Comparison of different methods of detection of enteric pathogenic protozoa. Indian J Med Microbiol 2013; 31: 154-160.

6. Bruijnesteijn van Coppenraet LE, Wallinga JA, Ruijs GJ, Bruins MJ, Verweij JJ. Parasitological diagnosis combining an internally controlled real-time PCR assay for the detection of four protozoa in stool samples with a testing algorithm for microscopy. Clin Microbiol Infect 2009; 15: 869-874.

7. Müller A, Bialek R, Fätkenheuer G, Salzberger B, Diehl V, Franzen C. Detection of Isospora belli by polymerase chain reaction using primers based on small-subunit ribosomal RNA sequences. Eur J Clin Microbiol Infect Dis 2000; 19: 631-634.

8. Taniuchi M, Verweij JJ, Sethabutr O, Bodhidatta L, Garcia L, Maro A, Kumburu H, Gratz J, Kibiki G, Houpt ER. Multiplex polymerase chain reaction method to detect Cyclospora, Cystoisospora, and microsporidia in stool samples. Diagn Microbiol Infect Dis 2011; 71: 386-390.

9. ten Hove RJ, van Lieshout L, Brienen EA, Perez MA, Verweij JJ. Real-time polymerase chain reaction for detection of Isospora belli in stool samples. Diagn Microbiol Infect Dis 2008; 61: 280-283.

10. Lalonde LF, Gajadhar AA. Detection and differentiation of coccidian oocysts by real-time PCR and melting curve analysis. J Parasitol 2001; 97: 725-730.

11. Taniuchi M, Verweij JJ, Sethabutr O, Bodhidatta L, Garcia L,
Maro A, Kumburu H, Gratz J, Kibiki G, Houpt ER. Multiplex polymerase chain reaction method to detect Cyclospora, Cystoisospora, and Microsporidia in stool samples. Diagn Microbiol Inf Dis 2011; 71: 386-390.

12. Wittwer CT, Reed GH, Gundry CN, Vandersteen JG, Pryor RJ. High-resolution genotyping by amplicon melting analysis using LC Green. Clin Chem 2003; 49: 853-860.

13. El-Shazly AM, Awad SE, Sultan DM, Sadek GS, Khalil HH, Morsy TA. Intestinal parasites in Dakahlia governorate with different techniques in diagnosing protozoa. J Egypt Soc Parasitol 2006; 36: 1023-1034.

14. Samarasinghe B, Johnson J, Ryan U. Phylogenetic analysis of Cystoisospora species at the rRNA ITS1 locus and development of a PCR-RFLP assay. Exp Parasitol 2008; 118: 592-595.

15. Yao H, Song J, Liu C, Luo K, Han J, Li Y, Pang X, Xu H, Zhu Y, Xiao P, Chen S. Use of ITS2 region as the universal DNA barcode for plants and animals. PLoS One 2010; 5: e13102.

16. Read SJ, Mitchell JL, Fink CG. Light cycler multiplex PCR for the laboratory diagnosis of common viral infections of the central nervous system. J Clin Microbiol 2001; 39: 3056-3059.

17. Ririe KM, Rasmussen RP, Wittwer CT. Product differentiation by analysis of DNA melting curves during the polymerase chain reaction. Anal Biochem 1997; 245: 154-160.

18. Yakovchuk P, Protozanova E, Frank-Kamenetskii MD. Basestacking and base-pairing contributions into thermal stability of the DNA double helix. Nucleic Acids Res 2006; 34: 564-574. 